\section{Imagery and repetition instructions in verbal discrimination learning as a function of lag*}

\author{
EDWARD J. ROWE + \\ University of Alberta, Edmonton, Alta., Canada
}

The effects of instructions to either repeat the correct item of each pair aloud more often than the incorrect item or to form an image to the correct item of each pair were studied in continuous verbal discrimination learning (VDL). The number of pairs intervening between study and test presentations varied from 0 to 64 . The imagery instruction was superior to repetition, which was better than an uninstructed control condition. In addition, the decline in performance with increasing lag was much less marked in the imagery instruction group. The results support the hypothesis that imagery and situational frequency are independent attributes in VDL, and suggest that the advantage accruing to the use of imagery occurs in the transfer of information from primary to secondary memory.

Situational word frequency has been clearly established as a significant variable in verbal discrimination learning (VDL). Numerous studies have demonstrated a strong facilitative effect of manipulations which serve to increase the frequency of occurrence of right ( $R$ ) relative to wrong (W) pair members. Such findings lend support to the frequency theory of VDL (Ekstrand, Wallace, \& Underwood, 1966), whereby Ss are said to acquire a verbal discrimination via several types of responses which produce a frequency incrementation favoring the $R$ items. Correct discrimination performance thus becomes a matter of choosing the more frequently occurring word of each pair.

Research on the effects of imagery in VDL (e.g., Rowe, 1972; Rowe \& Paivio, 1971) has demonstrated that (1) pairs of words rated high in im agery-arousing capacity (I) are considerably easier to learn than low-I pairs, and (2) Ss instructed to learn the discrimination list by forming an image to the $\mathrm{R}$ word of each pair do better than both control $S$ s and $S$ s who use a repetition strategy, i.e. differential overt rehearsal of the $R$ and $W$ items. Thus, it appears that imagery processes also strongly affect VDL performance. Furthermore, on the basis of a series of experiments which orthogonally contrasted the effects of imagery and frequency in VDL, Rowe (1972) has argued that the two variables exert independent and additive effects and that existing

* This research was conducted while the author held an Izaac Walton Killam postdoctoral fellowship at the University of Alberta. The assistance provided by $W$. $N$. Runquist and his staff is gratefully acknowledged. The data for this experiment were collected by Shannon Smith.

tRequests for reprints should be sent to Edward J. Rowe, Dept, of Psychology, Memorial University of Newfoundland, St. John's, Nfld., Canada. frequency theory is therefore inadequate as an explanation of the effect of imagery.

The present experiment constitutes a further test of the proposed independence of imagery and frequency mechanisms in VDL. A continuous presentation procedure was used to vary the number of intervening items (lag) occurring between the study and test presentations of different pairs within the list learned under either repetition or imagery instructions. A differential lag effect for the two instructional conditions would be evidence to support their hypothesized independence.

The Ss were 72 introductory psychology students at the University of Alberta, whose participation partially fulfilled a course requirement. They were assigned in rotation to one of three experimental conditions: imagery instruction, repetition instruction, and an uninstructed control.

The lists were constructed from a pool of 96 one-, two-, and three-syllable nouns, four to eight letters in length, selected from the Paivio, Yuille, \& Madigan (1968) norms. The words had I ratings above 6.00 on a 7-point scale and were greater than 39 per million by the Thorndike-Lorge frequency count. Two separate 48-pair lists were drawn up by a nonsystematic procedure, with intrapair associations being minimized by inspection and care being taken to see that the words in each pair did not differ by more than one syllable.

The pairs were presented to $S$ for one study and test trial in a continuous sequence. Each pair first occurred with the correct item underlined, then reappeared as a test item without the underlining after 0 , $1,8,16,32$, or 64 intervening pairs. Eight pairs were tested at each of the six levels of lag. A block-randomized schedule was used to construct the list, such that normally one pair was presented for testing at each lag before another item occurred at any lag value. Some departures from this schedule were necessary in order to maintain a convenient list length, but generally the study presentations of the items at each lag were distributed evenly throughout the list. Filler items were inserted in the sequence in the first two study positions to minimize any advantage accruing to early list position, and at 12 subsequent points in order to keep the lag schedule intact. These pairs comprised the same types of words as the others. Both of the lists had the same lag structure. Half of the pairs at each lag were tested with the left and right members reversed from the study trial, but for each list, the $R$ items appeared equally often on the right or on the left across pairs. As an added control, two additional lists were constructed, in which each $\mathbf{R}$ item from the original lists became the $W$ item in a given pair, and vice versa.

The word pairs, typed in capital Orator, were photographed as $16-\mathrm{mm}$ black and white negatives and presented on an Audiscan viewer at a 4 -sec rate. On each study trial, the $R$ word was underlined and $S$ pronounced both words aloud, reading from left to right. In addition, $S$ s in the repetition instruction condition were told to repeat the underlined word aloud three extra times, and Ss in the imagery group were told to form an image to the underlined word. It was stressed that Ss use only the particular technique described to them. Control Ss received no instructions concerning particular strategies. On the test trial for each pair, the underlining was absent and $S$ chose the word that he thought was correct. Guessing was encouraged. The experimental list was preceded by a practice list of four pairs tested at lags of 0,1 , and 4

\section{RESULTS AND DISCUSSION}

The mean number correct for the three instruction groups at each lag is shown in Fig. 1 . A 3 by 6 repeated-measures analysis of variance, with instruction and lag as factors, produced significant main effects for both instruction $[F(2,69)=23.28$, $\mathrm{p}<.001]$ and $\operatorname{lag}[\mathrm{F}(5,345)=21.79$, $p<.001]$, and a nonsignificant interaction $[F(10,345)=1.75]$. Newman-Keuls comparisons of the means for the three instruction groups collapsed across lag were carried out with an adopted significance level of .05. The imagery instruction was significantly superior to repetition, and both were superior to the control. A second repeated-measures analysis 


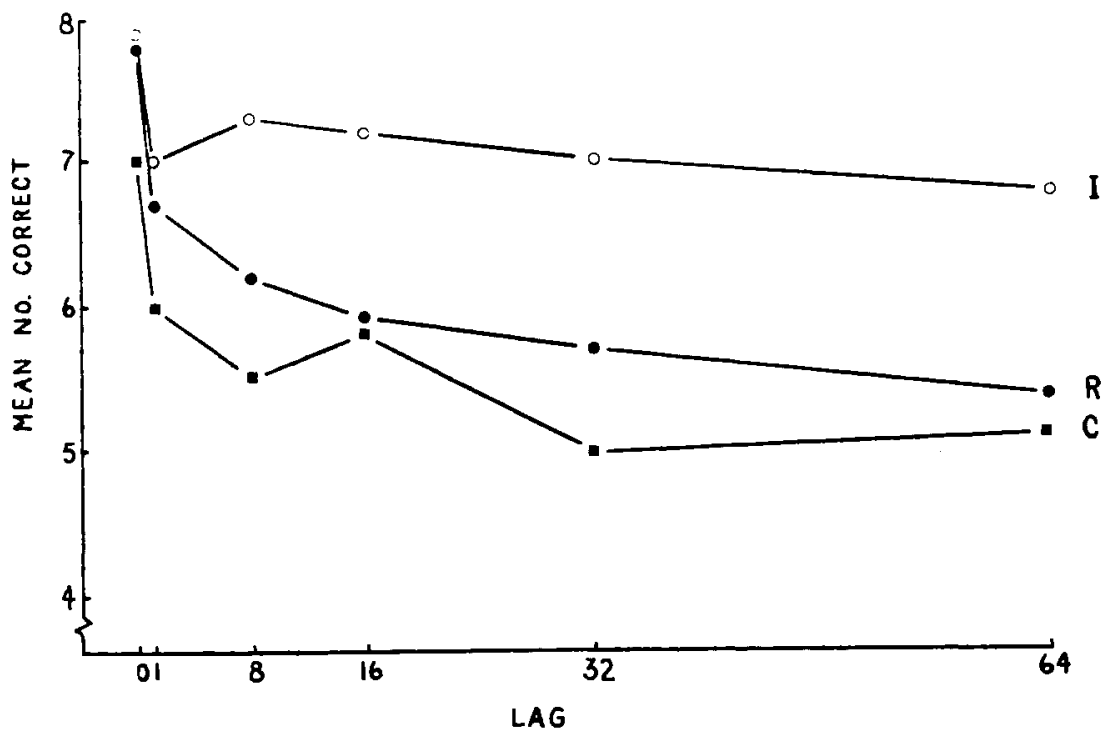

Fig. 1. Verbal discrimination as a function of lag for imagery (I), repetition $(R)$, and uninstructed control (C) conditions.

of variance was performed on the data for the repetition and imagery instruction groups alone in order to obtain a more sensitive test of the apparent interaction between instruction and lag. Both main effects were again significant, and the Instruction by $\mathrm{Lag}$ interaction produced a significant effect $[F(5,230)=3.60, \mathrm{p}<.01]$.

The overall ordering of the three instructional conditions in terms of their effects on VDL is identical to that found by Rowe \& Paivio (1971). The fact that the repetition group was superior to the control again confirms the effectiveness of situational frequency cues in this task and thus provides additional support for frequency theory. The superiority of the imagery instruction over the other two conditions is indicative of the strong influence of imagery processes and corroborates the finding (Rowe \& Paivio, 1971) that imagery instructions are more effective than repetition instructions in discrimination learning.

The differential form of the lag function for the imagery and repetition groups is further evidence for the independence of imagery and frequency processes in VDL. As shown in Fig. 1, performance in the regularly with increasing lag, whereas the overall rate of decline under imagery instructions is much less marked. The primary source of difference between the two functions, however, occurs between Lag 1 and Lag 8 , the slopes being very similar at shorter and longer lags. This indicates that the advantage accruing to the use of imagery as an encoding strategy might be localized in the transfer of information from a short- to a longer-term memory store. Once the information necessary for a correct discrimination has been stably represented in long-term memory, as is presumably the case after eight intervening items $(32 \mathrm{sec})$, the overall rate of loss is about the same for both instructional groups.

The above interpretation is supported by an examination of the repetition group falls off quite primary and secondary memory components of the imagery and repetition curves using the Waugh \& Norman (1965) probability analysis. By this procedure, the probability that a given item, $i$, is in primary memory $[P(i)]$ is given by the equation

$$
P(i)=\frac{R(i)-S(i)}{1-S(i)}
$$

where $R(i)$ is the probability of recall for item $i$ and $S(i)$ is the probability that item $i$ is in secondary memory. The latter can be estimated from the flat portion of a recall curve, and has the value .88 and .73 for imagery and repetition, respectively, in the present data (based on Lags 8-64 combined). The calculation of $P(i)$ by Eq. 1 for Lags 0 and 1 produced estimates of .93 and .37 for repetition instruction and .99 and .00 for imagery. These values indicate a more rapid loss of items from primary memory under imagery instructions. Since, according to the Waugh and Norman model, information lost from primary memory is either forgotten or transferred into secondary memory, and since very little forgetting occurred with imagery instructions, a facilitated transfer of information into secondary memory in this condition is implicated.

\section{REFERENCES}

EKSTRAND, B. R., WALLACE, W. P., \& UNDERWOOD, B. J. A frequency theory of verbal-discrimination learning. Psychological Review, 1966, 73, 556-578.

PAIVIO, A., YUILLE, J. C., \& MADIGAN, S. A. Concreteness, imagery, and meaningfulness values for 925 nouns. Journal of Experimental Psychology Monograph Supplement, 1968, 76(1), Part 2

ROWE, E. J. Imagery and frequency processes in verbal discrimination learning. Journal of Experimental Psychology, 1972, in press.

ROWE, E. J., \& PAIVIO, A. Imagery and repetition instructions in verbal discrimination and incidental paired-associate learning. Journal of Verbal Learning \& Verbal Behavior, $1971,10,668-672$.

WAUGH, N. C., \& NORMAN, D. A. Primary memory. Psychological Review, 1965, 72 , 89-104. 